\title{
Environmental correlates of the European common toad hybrid zone
}

\author{
Jan W. Arntzen \\ Naturalis Biodiversity Center, P.O. Box 9517, 2300 RA Leiden, The Netherlands \\ pim.arntzen@naturalis.nl \\ Daniele Canestrelli \\ Department of Ecological and Biological Science, Largo dell'Università s.n.c., \\ o110o Viterbo, Italy \\ canestrelli@unitus.it \\ Iñigo Martínez-Solano \\ Naturalis Biodiversity Center, P.O. Box 9517, 2300 RA Leiden, The Netherlands \\ Department of Biodiversity and Evolutionary Biology, Museo Nacional de Ciencias \\ Naturales, CSIC, c/ José Gutiérrez Abascal 2, 28006 Madrid, Spain \\ inigomsolano@mncn.csic.es
}

\begin{abstract}
The interplay between intrinsic (development, physiology, behavior) and extrinsic (landscape features, climate) factors determines the outcome of admixture processes in hybrid zones, in a continuum from complete genetic merger to full reproductive isolation. Here we assess the role of environmental correlates in shaping admixture patterns in the long hybrid zone formed by the toads Bufo bufo and B. spinosus in western Europe. We used species-specific diagnostic SNP markers to genotype 6584 individuals from 514 localities to describe the contact zone and tested for association with topographic, bioclimatic and land use variables. Variables related to temperature and precipitation contributed to accurately predict the distribution of pure populations of each species, but the models did not perform well in areas where genetically admixed populations occur. A sliding window approach proved useful to identify different sets of variables that are important in different sections of this long and heterogeneous hybrid zone, and offers good potential to predict the fate of moving contact zones in global change scenarios.
\end{abstract}

\section{Keywords}

Bufo bufo - Bufo spinosus - diagnostic SNP markers - France - Italy - two-species distribution model 


\section{Introduction}

The study of hybrid zones, or areas where individuals from two genetically differentiated population lineages meet and produce hybrid offspring, is critical to our understanding of how new species form and remain distinct through evolutionary time (Barton \& Hewitt, 1985; Harrison \& Larson, 2014). The outcome of this admixture process ranges from complete genetic merger to full reproductive isolation with strong selection against hybrid individuals, and is a result of the interaction between intrinsic and extrinsic factors (Mallet, 2005; Abbott et al., 2013). Among the former are developmental, physiological and behavioral traits contributing to reproductive isolation, whereas extrinsic factors include those associated with the spatial and climatic context of the hybrid zone.

Hybrid zones often extend for hundreds of kilometers across heterogeneous landscapes, with features like mountains, rivers, soil types or roads differentially restricting dispersal and, consequentially, the degree of admixture in alternate sections of the contact zone. Similarly, spatially varying climatic conditions along the hybrid zone potentially impose different selective pressures on parental species and their hybrids in different transects. While topography is generally more conserved through time, climatic changes operate at temporal scales that are relevant for the study of hybrid zone dynamics and have been invoked to explain patterns of asymmetrical introgression in moving hybrid zones. The study of the complex interplay of topographic and climatic factors varying over time and space in hybrid zones can thus illuminate the relative role of extrinsic factors in reproductive isolation, explain discordant genetic patterns in different sections of a hybrid zone, and help predict the fate of hybrid zones (i.e., the stability of reproductive isolation through time) in the face of climatic changes (McQuillan
\& Rice, 2015; Taylor et al., 2015; Hunter et al., 2017; Ryan et al., 2018).

The European common toad hybrid zone is an emerging model system in the study of speciation. The common (Bufo bufo (Linnaeus, 1758)) and spined (Bufo spinosus Daudin, 1803) toads meet along a ca. $900 \mathrm{~km}$ long hybrid zone from the Atlantic coast of northwest France to the Mediterranean coast of southeast France and northwest Italy (Recuero et al., 2012; Arntzen et al., 2018). This hybrid zone has been previously characterized with mitochondrial and nuclear DNA markers, which have revealed different patterns of genetic admixture across the hybrid zone, with transects in northwestern France resembling a classical tension zone model with selection against hybrids and those in the southeast of France and northwest of Italy characterized by strong cyto-nuclear discordance, probably as a result of spatial displacement of the hybrid zone in the past due to climatic changes (Arntzen et al., 2016, 2017; van Riemsdijk etal., 2019a, b).

While previous studies have discussed the potential role of intrinsic factors in maintaining reproductive isolation across the hybrid zone, the relative role of environmental correlates has not been assessed so far, with the exception of certain topographic features reported to be associated with genetic transitions in different section of the contact zone (Arntzen et al., 2017, 2018). Here we use environmental data and a comprehensive genetic dataset to investigate the role of extrinsic factors in maintaining species borders through space and time.

\section{Materials and methods}

A total of 6584 tissue samples was obtained from adult and larval toads from 514 localities across western Europe, with the emphasis on the broad region of species contact across France and Italy. Sampling was somewhat Downloaded from BPill. Com04/26/2023 12:53:02PM 
sparse at the Atlantic coast and it was unsuccessful over the lower cols of the French Alps (col de Montgenèvre at $1854 \mathrm{~m}$ a.s.l., colle della Maddalena at $1996 \mathrm{~m}$, col de Tende at $1870 \mathrm{~m}$ ). All sampled individuals were studied for the four species-diagnostic SNP nuclear markers bdnf, pomc, ragr and rpl3 (Arntzen et al., 2016). Individuals with data missing for more than one marker were excluded from the analysis. Population sample size ranged from $1-358$, with an average of 12.8. A total of 610 individuals was studied in duplicate. Results were not the same in two cases (0.08\%) and involved the score of ' 22 ' (i.e., homozygous for the spinosus-allele) versus the heterozygous ' 12 ' condition. Both observations were subsequently treated as unavailable. The total of missing data was $2.0 \%$. A subset of 2524 individuals from 185 localities was studied for another 27 diagnostic SNP markers (as in van Riemsdijk et al., 2019b; Arntzen, 2019) to determine the center of the two species contact zone more accurately. These latter localities were arranged in eight transects with hybrid zone centers located in France or Italy. For locality information, sample sizes and molecular species identifications see supplementary table S1. To visualize the locality information one can use the given link to the Naturalis depository, and openthis .kml filee.g., with Google Earth. Mitochondrial DNA and toad morphology were not studied because for these characters species diagnostic performances break down over parts of the species' parapatric range border (Arntzen et al., 2017, 2018).

The genetic data were subjected to Bayesian clustering with Structure software (Pritchard et al., 2000) with a predetermined $K$-value of two. The position of the mutual range border of B. bufo and B. spinosus was estimated by spatial interpolation of Structure $Q$-values, to obtain the $Q=0.5$ isoline. In the Structure analyses $K$ is the number of genetically differentiated genetic clusters and $Q$ equals the assignment probability for each investigated individual to belong to either cluster on a zero (B. spinosus) to unity scale (B. bufo). In this mapping exercise data per population were weighted by sample size and by the number of markers employed. We used Dirichlet cells with ILWIS (ILWIS, 2009) and linear interpolation with MyStat (Systat, 2007), which methods implied a weak and a strong spatial smoothing, respectively.

Environmental data considered include altitude and 19 climate variables from the WorldClim global climate database v2, available at http://www.worldclim.org (Hijmans et al., 2005; see also Fick \& Hijmans, 2017). The parameter 'slope' was derived from altitude through a set of filter operations. Soil properties data are from the ESDA European soil Database v2.o, available at https://esdac.jrc .ec.europa.eu (see also Panagos et al., 2012) and were used as far as parameter values could be ordered. Vegetation and land use data were from the CORINE land cover database of the European Environment Agency, available at https://www.eea.europa.eu/ publications/CORo-landcover. Data were grouped in the three classes 'crop growing', 'forestation' and 'pasture'.

To identify and subsequently reduce colinearity among the environmental variables we constructed the half-matrix of their pairwise Pearson correlation coefficients. This matrix was subjected to clustering with UPGMA. Variables were retained using criteria of partial independence at $\mathrm{r}<0.7$ and selected in alphanumeric order (supplemental fig. Si). The 20 variables considered for the construction of species distribution models are listed in table 1.

We produced two-species distribution models, in which both species' environmental attributes are contrasted under the assumption of a distribution in parapatry, as follows. First, we sampled environmental data for the localities of the genetically investigated toad populations within the area -5 to 12 degrees 
TABLE 1 Environmental variables considered for the construction of two-species distribution models for the common toad B. bufo and the spined toad B. spinosus. Note that the Corine data set constitutes one layer of information with three character states

\begin{tabular}{|c|c|}
\hline Class Environmental variable (unit) & Code \\
\hline $\begin{array}{l}\text { Climatic - WorldClim database } \\
\text { Annual mean temperature }(\mathrm{C}) \\
\text { Mean diurnal range }(\mathrm{C}) \\
\text { Isothermality } \\
\text { Temperature seasonality } \\
\text { Minimum temperature of coldest month }(\mathrm{C}) \\
\text { Mean temperature of wettest quarter }(\mathrm{C}) \\
\text { Mean temperature of driest quarter }(\mathrm{C}) \\
\text { Annual precipitation }(\mathrm{mm}) \\
\text { Precipitation of driest month }(\mathrm{mm}) \\
\text { Precipitation seasonality }\end{array}$ & $\begin{array}{l}\text { Bioo1 } \\
\text { Bioo2 } \\
\text { Bioo3 } \\
\text { Bioo4 } \\
\text { Bioo6 } \\
\text { Bioo8 } \\
\text { Bioo9 } \\
\text { Bio12 } \\
\text { Bio14 } \\
\text { Bio15 }\end{array}$ \\
\hline $\begin{array}{l}\text { Topographical - WorldClim database } \\
\text { Altitude (m a.s.l.) }\end{array}$ & Alt \\
\hline $\begin{array}{l}\text { Soil properties - ESDAC database } \\
\text { Dominant limitation to agricultural use } \\
\text { (recoded as no limitation, gravelly, stony and lithic) } \\
\text { Total available water content (mm, } 7 \text { classes) } \\
\text { Bulk density }\left(\mathrm{g} \mathrm{cm}^{-3}, 10 \text { classes) }\right. \\
\text { Soil crusting (very weak to very strong, } 5 \text { classes) } \\
\text { Depth to rock (cm, } 4 \text { classes) } \\
\text { Topsoil easily available water capacity (mm/m, } 4 \text { classes) } \\
\text { Sand (\%) } \\
\text { Annual average soil water regime } \\
\text { (depth in cm and duration in months, } 4 \text { classes) }\end{array}$ & $\begin{array}{l}\text { Aglimı } \\
\text { Awc } \\
\text { Bd } \\
\text { Crusting } \\
\text { Dr } \\
\text { Eawctop } \\
\text { Sand }\end{array}$ \\
\hline $\begin{array}{l}\text { Land use and vegetation (categorical) - Corine database } \\
\text { Crop growing (classes 12-17, 19-21) } \\
\text { Forestation (classes 22-25) } \\
\text { Pasture (class 18) }\end{array}$ & $\begin{array}{l}\text { Crop } \\
\text { Forest } \\
\text { Pasture }\end{array}$ \\
\hline
\end{tabular}

eastern longitude and 42 to 53 degrees northern latitude. Populations with $Q<0.2$ that represent $B$. bufo and $Q>0.8$ that represent $B$. spinosus were about equally frequent $(B$. bufo $N=$ 196, B. spinosus $N=208$ ). The cut-off levels at 0.2 and 0.8 are according to Endler (1977). Data for 47 populations with intermediate $Q$-values were analyzed separately. This refers to the fact that only climatic data from 'pure' populations were used to build the logistic regression (twospecies) model, but once the model was built, climatic data from these 47 admixed populations were entered in the resulting logistic equation to test for a possible correlation between Structure Q-scores and AUC model fit.

Second, environmental data were sampled in a string of 17 overlapping and adjoining circular windows, positioned over the species contact zone, as defined by the $Q=0.5$ isoline (fig. 1). A window diameter of $100 \mathrm{~km}$ was chosen to widely encompass the ca. $50 \mathrm{~km}$ wide B. bufo - B. spinosus hybrid zone (Arntzen et al., 2016, 2017, 2018; van Riemsdijk et al., $2019 \mathrm{~b})$. In consideration of scale, the string of windows followed the smooth, curved species delineation (and not the more angular one; see below). The analyses involved 
Northern latitude

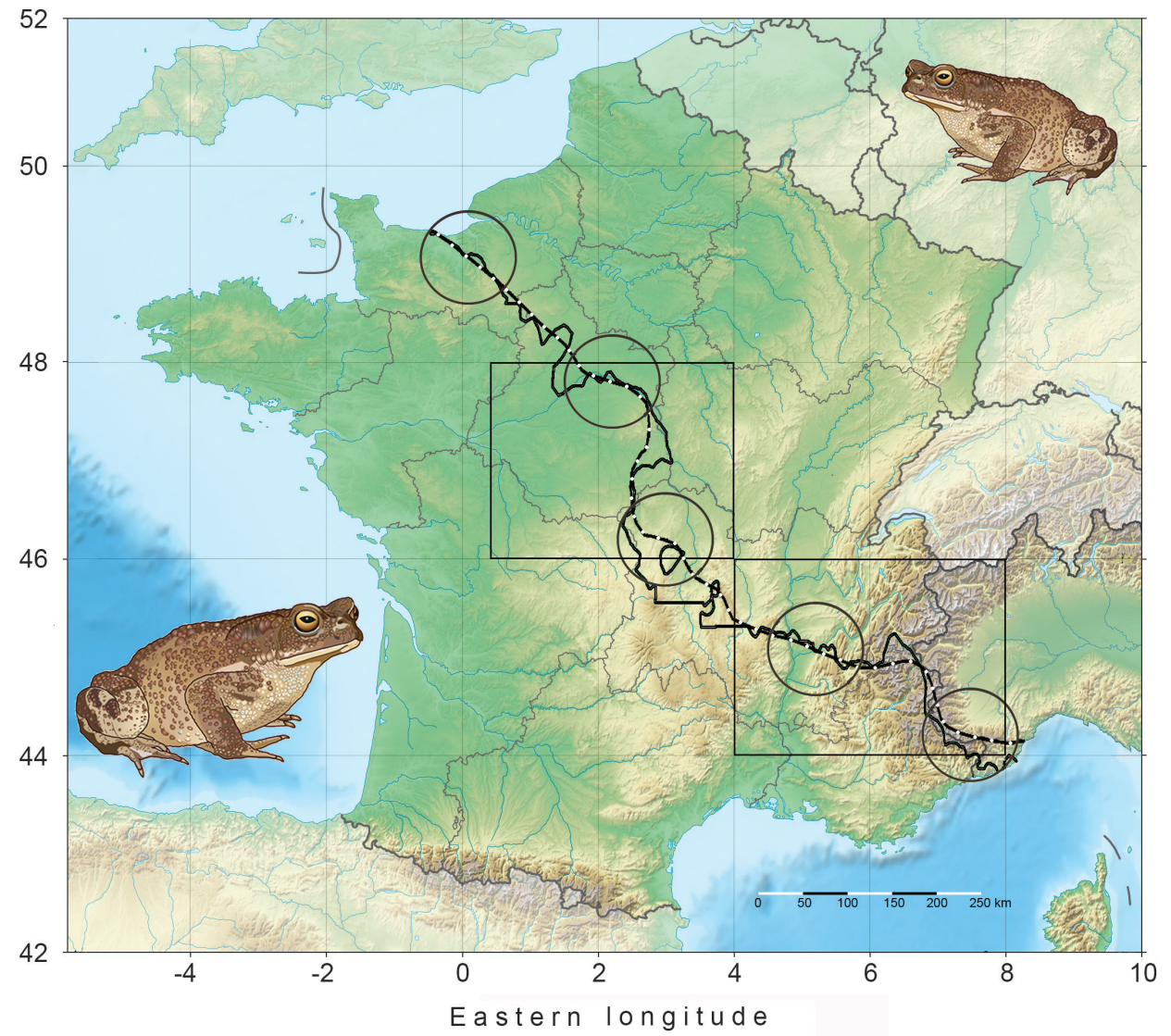

FIGURE 1 Western Europe with France and adjacent countries in Mercator projection. Colours from green to brown indicate increasing altitudes. The Bufo bufo versus B. spinosus mutual range delineation is based upon molecular genetic data, in which the smooth interrupted line is derived by linear interpolation whereas the more angular line is based upon Dirichlet cells (for details see text). The small bodied common toad B. bufo occurs to the northeast and the large bodied spined toad B. spinosus to the southwest of the mutual range border. Environmental data were gathered for 17 overlapping and adjoining circular windows positioned over the mutual range border. Here shown are window 1 in the northwest of France, window 17 in the northwest of Italy and windows 5, 9 and 13 in between. The two boxed areas are highlighted in fig. 3. The base map was downloaded from MapsLand at https://www .mapsland.com, under a Creative Commons Attribution-ShareAlike 3.o Licence. The animal drawings are by Bas Blankevoort, Naturalis Biodiversity Center.

100 randomly chosen data points per window. The sampling localities were interpreted as pseudo-presences of $B$. bufo $\left(N \sim 5^{\circ}\right.$ per window $)$ and $B$. spinosus $\left(N \sim 5^{\circ}\right.$ per window $)$ if at the northeastern or at the southwestern side of the inferred species border, respectively. Subsequently, logistic regression analyses were performed with 'species' as the dependent variable versus one categorical and 19 continuous environmental explanatory variables (table 1). Parameter selection was in the forward stepwise mode under the criteria of $P_{\text {in }}=$ 0.05 and $P_{\text {out }}=0.10$ under the likelihood ratio criterion. Model fit was assessed by the area under the curve (AUC) statistic. Data statistical analyses were with SPSS 20 (IBM SPSS, 
2016) and distribution models were visualized with ILWIS (ILWIS, 2009).

\section{Results}

The nuclear genetic data confirm that the hybrid zone of the common toad, B. bufo and the spined toad, $B$. spinosus, runs from the Atlantic coast to the Mediterranean (fig. 1). The smooth and more angular estimates of the mutual species range delimitation run in parallel, with relatively large deviations from one another near the city of Orleans (window 4), the northern foothills of the Plateau Central (windows 9 and 10) and the French Alps (window 15). The selected two-species distribution model is represented by the logistic equation $P_{\mathrm{b}}=\left(1 /\left(1+\exp \left(0.0167^{*}\right.\right.\right.$ alt + $0.243^{*}$ bioo1 $+1.307^{*}$ bioo3 $+0.179^{*}$ bioo6$0.0357^{*}$ bioo $8+0.0105^{*}$ bioog -0.00856 *bio12 + $0.0195^{*}$ sand -69.899$\left.)\right)$ ), in which $P_{\mathrm{b}}$ is the probability of occurrence of $B$. bufo on a zero to unity scale (fig. 2 ), alt is altitude in $m$ a.s.l., bioo1 is annual mean temperature in $\mathrm{C}$, bioo3 is isothermality, bioo6 is the minimum temperature of the coldest month $(\mathrm{C})$, bioo8 is the mean temperature of the wettest quarter $(\mathrm{C})$, bioog is the mean temperature of the driest quarter $(\mathrm{C})$, bio12 is the annual precipitation in $\mathrm{mm}$ and sand is the percentage sand soil composition. The AUC model fit is 0.97. This model applied to 47 genetically admixed toad populations shows no significant correlation of the Structure $Q$-value and AUC model fit $(r=0.157, P>0.05)$. Model fit over each of the 17 windows varied from 'less than good' (AUC $<0.8$ ) at windows 1, 6-8 and 14-16, to 'good' or 'very good' for windows $2,3,5,12,13$ and 17 and approached unity at windows 4 and 9-11. Low model fit largely coincides with areas where i) sampling is sparse (window 1), ii) where rivers separate the species' ranges, namely the Loire and the Cher at windows $5^{-8}$ (fig. $3 \mathrm{~A}$ ) and the Rhône-Isère at windows 13-14, and iii) the Alps, where both species are thinly distributed (windows $15^{-16}$ ) (fig. $3^{3}$ ). Evaluation of the performance of the eight selected variables over the remaining windows (i.e., windows $2-4,9-12$ and 17) shows qualitatively consistent results for altitude, bioo3 and bioo8, with lower values for B. bufo than for B. spinosus (fig. 4). However, parameter values vary markedly along the contact zone with, for example, the mutual species border being located at altitudes of ca. $200 \mathrm{~m}$ a.s.l. in the west of France, at ca. $500 \mathrm{~m}$ at the Plateau Central and at ca. $1200 \mathrm{~m}$ in the Ligurian Alps. The reverse situation with $B$. bufo at higher altitudes than B. spinosus is found at window 6 , which coincides with the Loire river. The parameters bioog and bio12 also show contrasting values over different sections of the contact zone. Finally, the parameters bioo1, bioo6 and sand show few or minor inconsistencies.

\section{Discussion}

We used two approaches to assess the role of environmental variables in shaping the common-spined toad hybrid zone. While both performed relatively well at predicting where pure populations will be, the global model performed poorly when genetically admixed populations were considered. This may reflect the heterogeneity of the hybrid zone, where the spatial context of successive transects varies greatly in association with topography. Our results also highlight the sliding window approach as most useful for dealing with long, complex hybrid zones, because different variables will have different impact on hybrid zone structure in different sections of the zone, and these are highlighted as such. 
Northern latitude

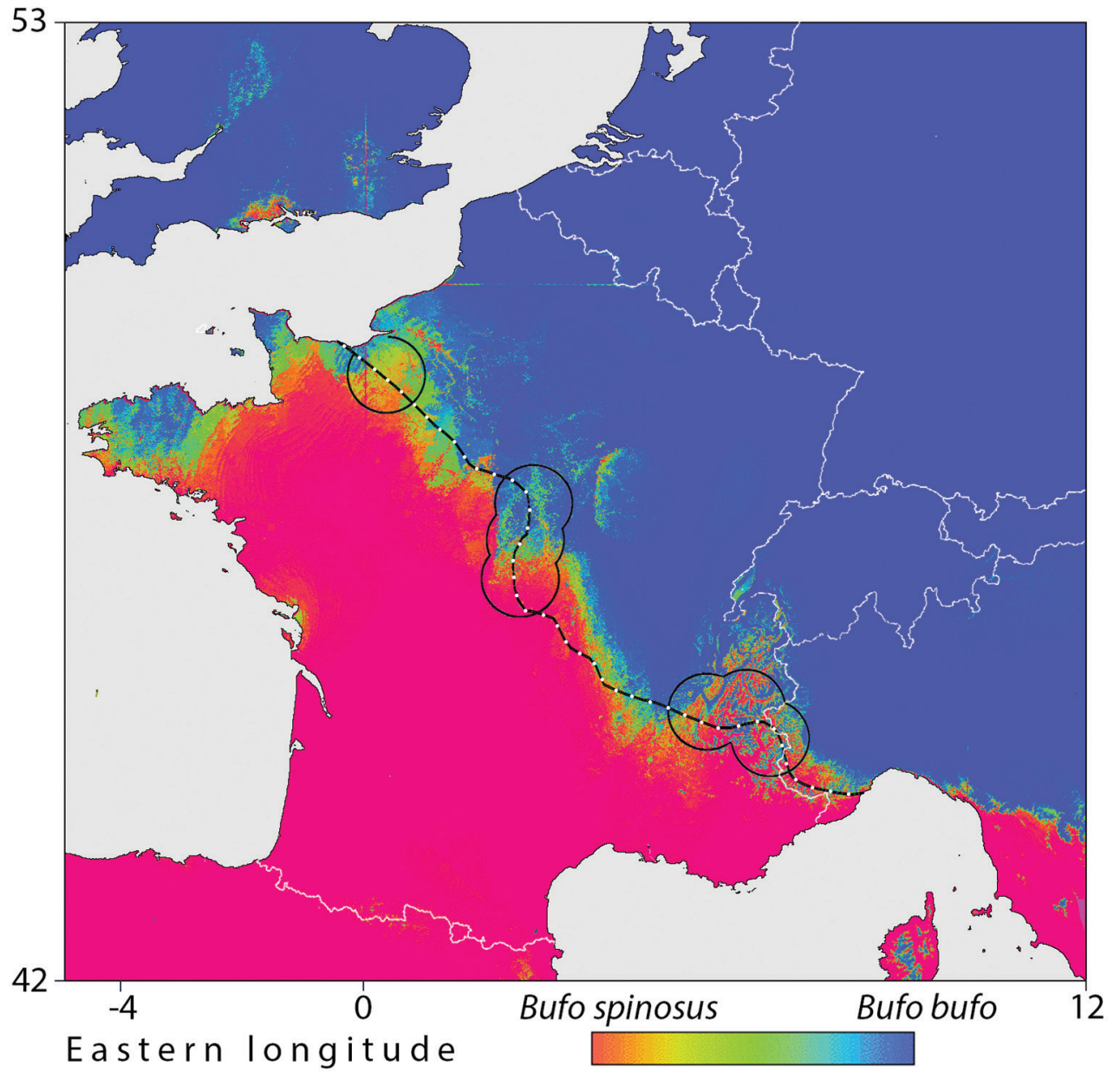

FIgURE 2 Two-species 'global' distribution model for Bufo toads in western Europe. The colour scale runs from deep red for B. spinosus ( $P_{\mathrm{b}}$ is zero) to deep blue for B. bufo $\left(P_{\mathrm{b}}\right.$ at unity). The interrupted black line represents the center of the species' hybrid zone from molecular data, as in fig. 1. Outlined circular windows are those for which model fit is less than good (AUC < 0.8, windows 1, 6-8 and 14-16).

Among selected environmental variables, most were related to temperature (bioo1, bioo3, bioo6, bioo8, bioog) or precipitation (bio12), but soil type also entered the global model. While the former may generally be associated with a differentiation between a northern (cooler, more humid) and a southern (warmer, drier and more extreme) species, the role of soil type is not obvious, and may have an indirect association with the distribution of the two toad species (e.g., through larval or postmetamorphic associations with $\mathrm{pH}$ and vegetal communities). However, land use categories did not make it into the models, but perhaps they operate at a smaller spatial scale and have little or no bearing on the wider position of the hybrid zone.

High model fit was also associated with higher altitudes for $B$. spinosus than for $B$. bufo. This observation is not compatible with the climate preferences alluded to in the above, with as a further complication that the critical altitude increases with an increasingly continental climate. Low model 

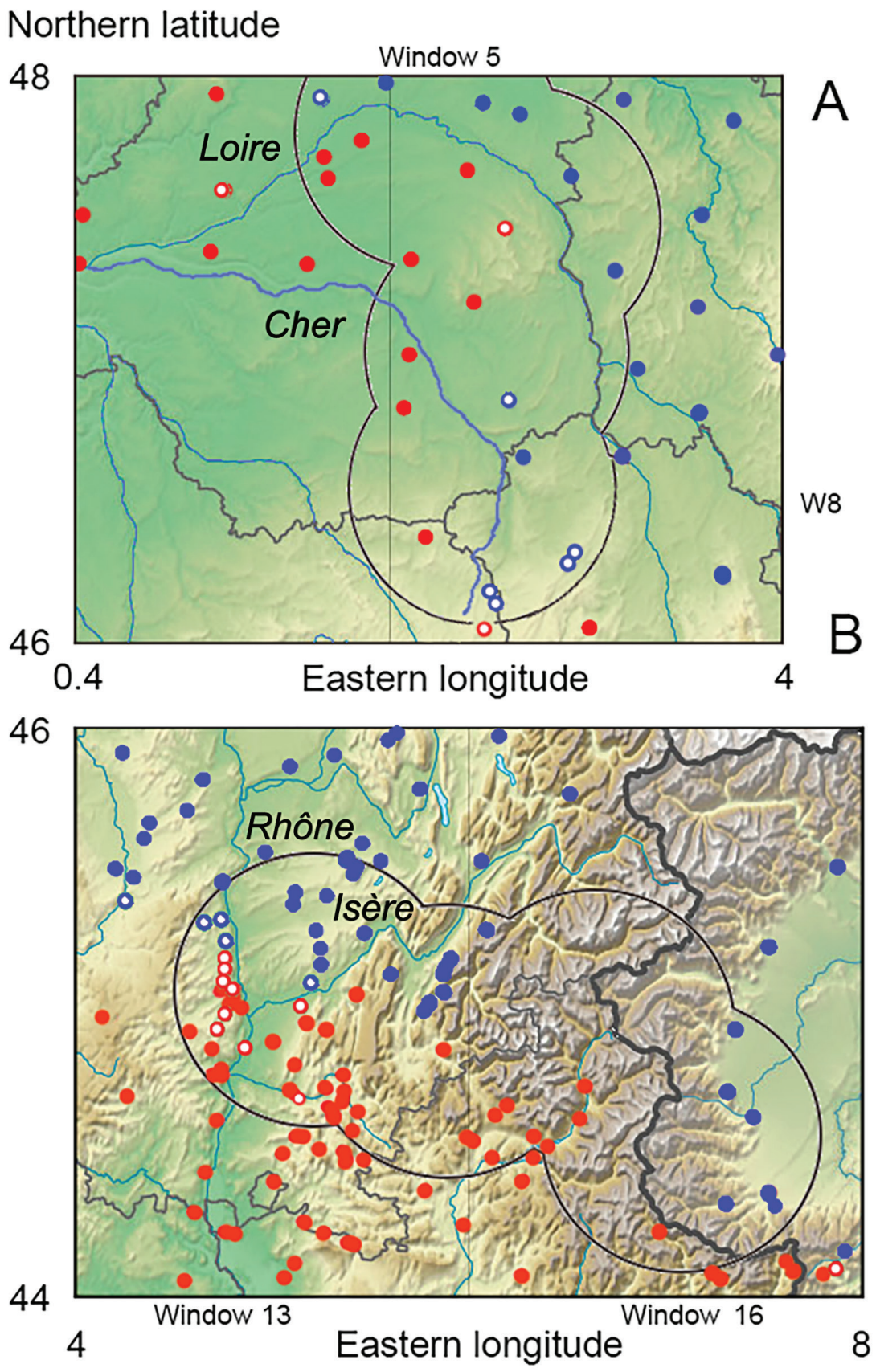

FIGURE 3 Two regions in the common-spined toad hybrid zone where the mutual species border appears to coincide with rivers. Coloured dots indicate toad populations with nuclear genetic species identifications as Bufo bufo $\left(Q=P_{\mathrm{b}}>0.5\right.$, blue symbols $)$ and $B$. spinosus $\left(Q=P_{\mathrm{b}}<0.5\right.$, red symbols $)$. Open dots have $Q$-values in the $0.2-0.8$ range. For numerical detail see supplementary table $\mathrm{S}$. Base map figure credits as in fig. 1. A) central France where the species border appears to coincide with the northernmost sections of the Loire (windows 5 and 6) and the upper stretches of the Cher (windows 7 and 8). B) southeastern France where the species border coincides with the Rhône and the lower Isère river at window 13. Note the paucity of data for the high Alps at windows 15 and 16 (see also Lescure and de Massary, 2012; Arntzen et al., 2017). 

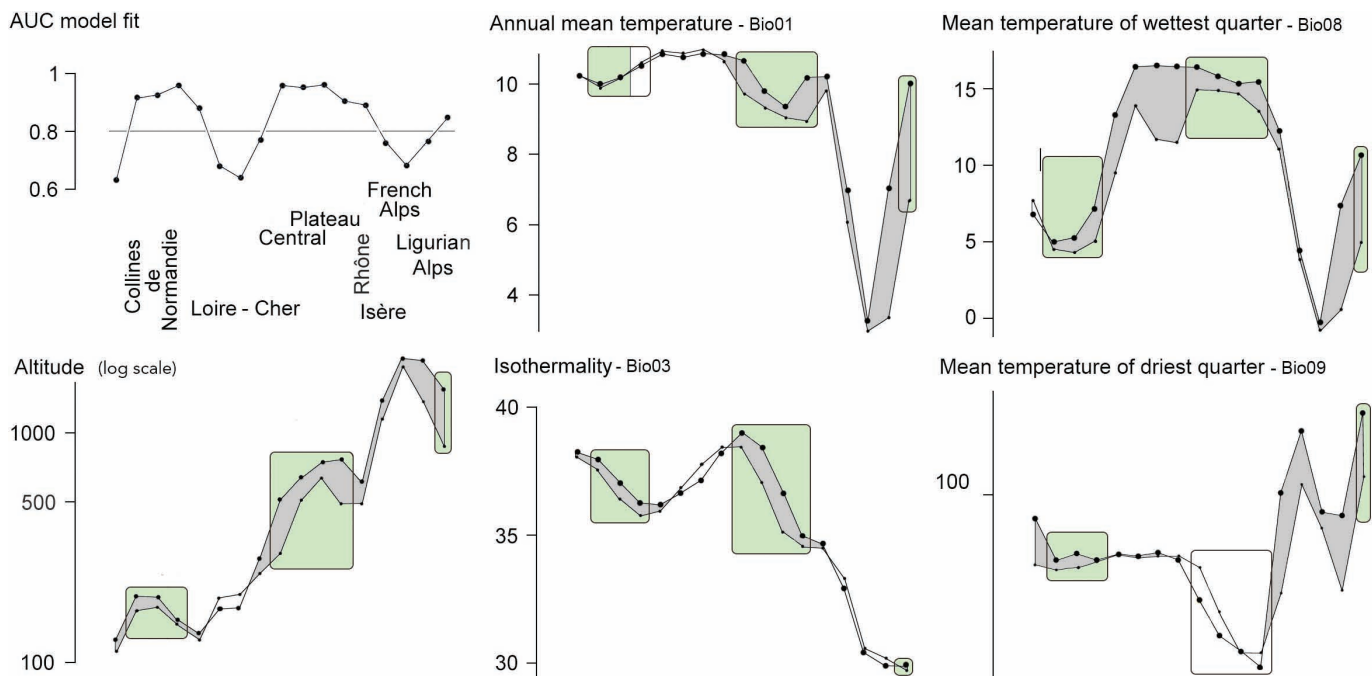

Isothermality- Bio03

Mean temperature of driest quarter - Bio09
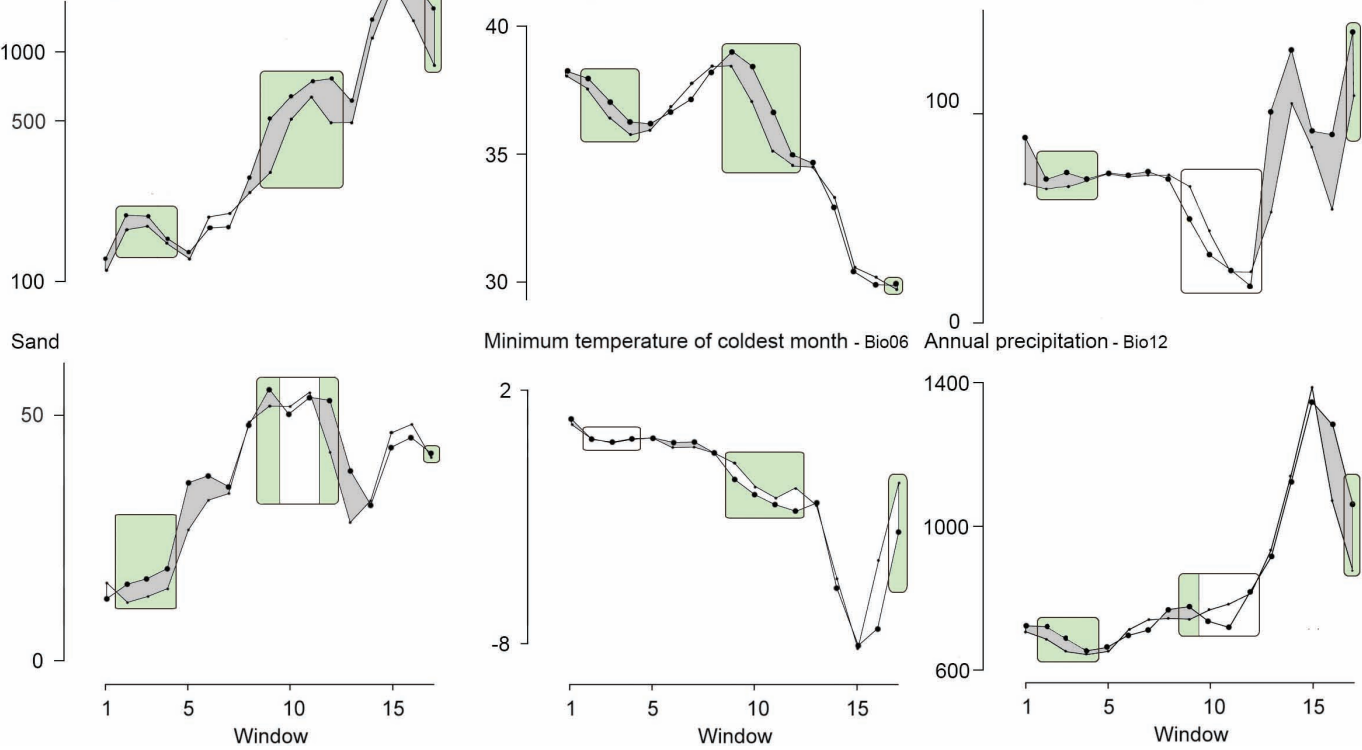

Minimum temperature of coldest month - Bio06
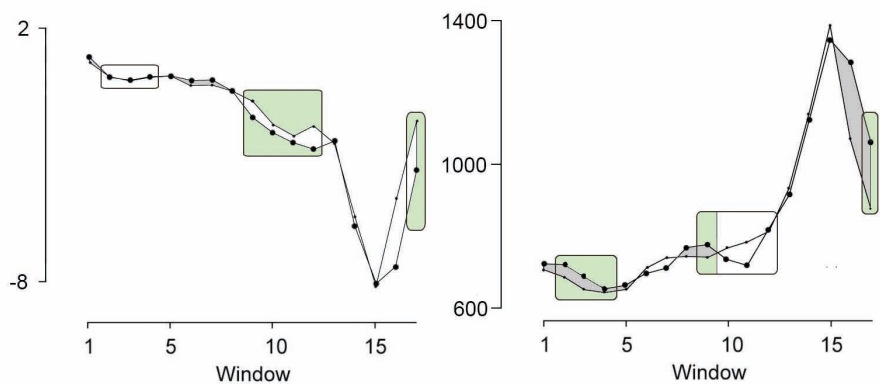

FIGURE 4 Average values for eight environmental variables over 17 windows that follow the Bufo bufo - B. spinosus hybrid zone from the Atlantic coast (window 1) to the Mediterranean (window 17). Variables shown are those selected by a logistic regression analysis, with 'species' as dependent variable and explanatory variables available for selection as in table 1. Units are as in table 1; see also Hijmans et al. (2005). Values for B. bufo and B. spinosus are shown by small and large dots, respectively. Grey areas indicate that values for $B$. bufo are lower than for $B$. spinosus. The graph at the top left provides AUC model fit values along with major topographical references. Rectangles indicate stretches of the species contact for which the environmental models have good fit (AUC $>0.8$ ), with consistent results indicated by green shadings. For the other windows with less than good model fit, signals are likely to be absent or void, either from poor sampling (window 1), the presence of rivers (windows $5^{-9}, 1^{-14}$ ), or a thin or absent species' contact (windows 16-17) (see fig. 3).

fit tended to be associated with less (toad) populated areas and with rivers. These are areas where dispersal is reduced and where moving hybrid zones are predicted to settle (Barton \& Hewitt, 1985). The highest records for B. bufo are from the Swiss Alps at 2300 m (Malkmus \& Grossenbacher, 2013) where the species is expanding its elevation range (Luscher et al., 2016). The highest records for B. spinosus are from the Pyrenees at 2600 $\mathrm{m}$ with, however, low population densities above 1500 m (Balcells, 1975; Ortiz Santaliestra, 2014). We were unable to find toads on the mountain passes from France to Italy and it is currently unclear to what degree the two species are (or perhaps were) locally in contact, other than towards the Mediterranean coast. 
Our study shows that rivers can have a larger impact than climatic/environmental variables, suggesting that the presence of a river can break down environmental associations with toad presence. The low numerical model fit at rivers may simply reflect the fact that these linear structures were not incorporated in our two-dimensional modelling approach. Historical factors can also overrule the importance of environmental variables, for instance when different regions involve different intraspecific lineages, such as the northern Balkan lineage of B. bufo and its southern, Apennine counterpart (Garcia-Porta et al., 2012; Arntzen et al., 2017). Bufo bufo from the Mediterranean region frequently show morphological characteristics of Iberian B. spinosus, such as a spined skin, widely positioned parotoid glands and large body size, resulting in coinciding spatial patterns for morphology and environment. The failure of the model to accurately predict the species present in Normandy and Brittany may be a 'preoccupancy effect', where a species is present in an area that is more environmentally favourable for the other species just because it has been long part of its range. Alternatively, B. bufo might have occupied these areas but did not make it because the colonization route was inaccessible (Arntzen, 2019), or these western French areas represent environmental conditions that are out of range for the area over which the model was developed. A more fundamental drawback of the two-species modelling as here employed is that areas without either species are not recognized as such. An example of this phenomenon in the current data set is Corsica where environmental conditions appear more suitable for $B$. spinosus in the coastal regions and more suitable for $B$. bufo at the mountainous interior of the island, yet both species are absent (Agasyan et al., 2009). The above observations illustrate that there is an upper bound to the spatial range over which a two-species distribution model might reasonably be extrapolated.

Predicting the fate of moving hybrid zones is challenging because of the complex interaction between topography and environmental variables, but our sliding window approach, coupled with phylogeographic analyses, would seem to offer great potential to make predictions on species advances and retreats in a global change scenario.

\section{Acknowledgements}

We thank Gaëlle Caublot, Jacob McAtear, Rob Veen and the late Annie Zuiderwijk for help with tissue collecting.

\section{Supplementary material}

Supplementary material is available online at: https://doi.org/10.6o84/m9.figshare.11931627.

Additional supplementary information can be found at https://www.repository.naturalis. $\mathrm{nl} /$ record/710370. This contains a .kml-file with species occurences that can be inspected e.g., with Google Earth.

\section{References}

Abbott, R., Albach, D., Ansell, S., Arntzen, J.W., Baird, S.J.E., Bierne, N., Boughman, J.W., Brelsford, A., Buerkle, C.A., Buggs, R., Butlin, R.K., Dieckmann, U., Eroukhmanoff, F., Grill, A., Cahan, S.H., Hermansen, J.S., Hewitt, G., Hudson, A.G., Jiggins, C., Jones, J., Keller, B., Marczewski, T., Mallet, J., Martinez-Rodriguez, P., Moest, M., Mullen, S., Nichols, R., Nolte, A.W., Parisod, C., Pfennig, K., Rice, A.M., Ritchie, M.G., Seifert, B., Smadja, C.M., Stelkens, R., Szymura, J.M., Vainola, R., Wolf J.B.W. \& Zinner, D. (2013) Hybridization and speciation.J. Evol. Biol., 26, 229-246. doi:10.1111/j.1420-9101.2012.02599.x. 
Agasyan, A., Avisi, A., Tuniyev, B., CrnobrnjaIsailovic, J., Lymberakis, P., Andrén, C., Cogalniceanu, D., Wilkinson, J., Ananjeva, N., Üzüm, N., Orlov, N., Podloucky, R., Tuniyev, S. \& Kaya, U. (2009) Bufo bufo. The IUCN Red List of Threatened Species 2009. doi:10.2305/IUCN .UK.2009.RLTS.T54596A11159939.en.

Arntzen, J.W. (2019) An amphibian species pushed out of Britain by a moving hybrid zone. Mol. Ecol., 28, 5145-5154. doi:10.1111/mec.15285.

Arntzen, J.W., de Vries, W., Canestrelli, D. \& Martínez-Solano, I. (2017) Hybrid zone formation and contrasting outcomes of secondary contact over transects in common toads. Mol. Ecol., 26, 5663-5675. doi:10.1111/mec.14273.

Arntzen, J.W., McAtear, J., Butôt, R. \& MartínezSolano, I. (2018) A common toad hybrid zone that runs from the Atlantic to the Mediterranean. Amphibia-Reptilia, 39, 41-50. Doi:10.1163/ 15685381-00003145.

Arntzen, J.W., Trujillo, T., Butôt, R., Vrieling, K. \& Schaap, O.D., Gutiérrez-Rodriquez, J. \& Martínez-Solano, I. (2016) Concordant morphological and molecular clines in a contact zone of the common and spined toad (Bufo bufo and B. spinosus) in the northwest of France. Front. Zool., 13, 1-12. doi:10.1186/s12983-016-0184-7.

Balcells, E. (1975). Observaciones sobre el ciclo biológico de anfibios de alta montaña y su interés en la detección del inicio de la estación vegetativa. Publicaciones del Instituto de Biología Aplicada, 7, 55-153.

Barton, N.H. \& Hewitt, G.M. (1985) Analysis of hybrid zones. Annu. Rev. Ecol. Evol. Syst., 16, 113148. doi:10.1146/annurev.es.16.110185.000553.

Endler, J.A. (1977) Geographic Variation, Speciation, and Clines. Monographs in Population Biology 18. Princeton University Press, Princeton.

Fick, S.E. \& R.J. Hijmans (2017) Worldclim 2: New $1-\mathrm{km}$ spatial resolution climate surfaces for global land areas. Int. J. Climatol., 37, 4302-4315. doi:10.1002/joc.5086.

Garcia-Porta, J., Litvinchuk, S.N., Crochet, P.A., Romano, A., Geniez, P.H., Lo-Valvo, M., Lym- berakis, P. \& Carranza, S. (2012) Molecular phylogenetics and historical biogeography of the west-palearctic common toads (Bufo bufo species complex). Mol. Phylogenet. Evol., 63, 113-130. doi:10.1016/j.ympev.2011.12.o19.

Hijmans, R.J., Cameron, S.E., Parra, J.L., Jones, P.G. \& Jarvis, A. (2005) Very high resolution interpolated climate surfaces for global land areas. Int. J. Climatol., 25, 1965-1978. doi:10.1002/joc.1276.

Hunter, E.A., Matocq, M.D., Murphy, P.J. \& Shoemaker, K.T. (2017) Differential effects of climate on survival rates drive hybrid zone movement. Curr. Biol., 27, 3898-3903. doi:10.1016/j .cub.2017.11.029.

IBM SPSS (2016) Statistical Package for the Social Sciences. SPSS Inc., Chicago.

ILWIS (2009). Integrated Land and Water Information System (ILWIS). Open software version 3.6. ITC, Enschede.

Lescure, J. \& de Massary, J.C. (2012) Atlas des Amphibiens et Reptiles de France. Biotope: Muséum National d'Histoire Naturelle, Paris.

Luscher, B., Beer, S. \& Grossenbacher, K. (2016) Die Höhenverbreitung der Erdkrote (Bufo bufo) im Berner Oberland (Schweiz) unter sich verändernden Klimabedingungen. Z. Feldherpetol., $23,47-58$.

Malkmus, R. \& Grossenbacher, K. (2013) Fortpflanzungserfolg der Erdkröte (Bufo bufo) in hochalpinen Gewässern. Z. Feldherpetol., 20, 102-04.

Mallet, J. (2005) Hybridization as an invasion of the genome. Trends Ecol. Evol., 20, 229-237. doi:10.1016/j.tree.2005.02.010.

McQuillan, M.A. \& Rice, A.M. (2015) Differential effects of climate and species interactions on range limits at a hybrid zone: potential direct and indirect impacts of climate change. Ecol. Evol., 5, 5120-5137. doi:10.1002/ece3.1774.

Ortiz Santaliestra, M.E. (2014) Sapo común - Bufo spinosus. In: A. Salvador \& I. Martínez-Solano (Eds) Enciclopedia Virtual de los Vertebrados Españoles. Museo Nacional de Ciencias Naturales, Madrid, Spain. http://www.vertebradosiberi cos.org. 
Panagos P., Van Liedekerke M., Jones A. \& Montanarella L. (2012) European Soil Data Centre: Response to European policy support and public data requirements. Land Use Policy, 29, 329338. doi:10.1016/j.landusepol.2011.07.003.

Pritchard, J.K., Stephens, M. \& Donnelly, P. (2000) Inference of population structure using multilocus genotype data. Genetics, 155, 945-959.

Recuero, E., Canestrelli, D., Vörös, J., Szabó, K., Poyarkov, N.A., Arntzen, J.W., CrnobrnjaIsailovic, J., Kidov, A.A., Cogălniceanu, D., Caputo, F.P. \& Nascetti, G. (2012) Multilocus species tree analyses resolve the radiation of the widespread Bufo bufo species group (Anura, Bufonidae). Mol. Phylogenet. Evol., 62,71-86. doi:10.1016/j.ympev.2011.09.008.

Riemsdijk, I. van, Arntzen, J.W., Butlin, R.K., Bucchiarelli, G., McCartney-Melstad, E., Rafajlovic, M., Scott, P., Toffelmier, E., Shaffer, B. \& Wielstra, B. (2019a) Spatial variation in introgression along the common toad hybrid zone. In: I. van Riemsdijk, Hybrid Zone Dynamics in
Amphibians, pp. 81-97, PhD-thesis. Naturalis Biodiversity Centre and the Institute of Biology at Leiden University, Leiden.

Riemsdijk, I. van, Butlin, R.K., Wielstra, B. \& Arntzen, J.W. (2019b) Testing an hypothesis of hybrid zone movement for toads in France. Mol. Ecol., 28, 1070-1083. doi:10.1111/mec.15005.

Ryan, S.F., Deines, J.M., Scriber, J.M., Pfrender, M.E., Jones, S.E., Emrich, S.J. \& Hellmann, J.J. (2018) Climate-mediated hybrid zone movement revealed with genomics, museum collection, and simulation modeling. Proc. Natl. Acad. Sci., 115, E2284-2291. doi:10.1073/pnas.1714950115.

Systat (2007) Mystat 12. Systat Software, San Jose.

Taylor, S.A., Larson, E.L. \& Harrison. R.G. (2015) Hybrid zones: windows on climate change. Trends Ecol. Evol., 30, 398-406. doi:10.1016/j .tree.2015.04.010.

RECEIVED: 8 OCTOBER 2019 | REVISED AND

ACCEPTED: 28 FEBRUARY 2020

EDITOR: A. IVANOVIĆ 